\title{
CALCULATION OF THE NATURAL FREQUENCIES OF A BEAM- MASS SYSTEM USING FINITE ELEMENT METHOD
}

\author{
H. R. Öz \\ Department of Mechanical Engineering, Celal Bayar University, 45140 Manisa, Turkey
}

\begin{abstract}
In this study, the natural frequencies of an Euler-Bernoulli type beam with a mass are calculated. The beam is supported with different end conditions. The mass is located on different locations. The linear natural frequencies are calculated by using finite element method for the first five modes. Results are compared with those of exact and other approximate methods.
\end{abstract}

\section{INTRODUCTION}

Beam-mass systems have been investigated by many researchers. The natural frequencies of beam-mass systems, plates carrying concentrated masses under different boundary conditions were calculated by using approximate and exact analysis [1-4] and two fundamental theories of beam vibrations were compared [5]. Chai and Low [6] investigated the natural frequencies of a beam with a mass near the beam's ends. Low et al. [7] found that the results of experiments and the theory did not match well for beams of large slenderness ratio for centre loaded beams. Chai et al. [8] and Low et al. [9] presented both experimental and theoretical results using Rayleigh-Ritz procedure and showed that the correlation between theory and experiments was much improved when stretching effects were included [9]. Özkaya et al. [10] analyzed non-linear free and forced vibrations of a beam-mass system by considering five different sets of boundary conditions. The authors investigated the effects of the location and the magnitude of the mass on the natural frequencies. They used a perturbation technique in the analysis. Low [11] used different assumed shape functions to obtain the kinetic and potential energies of the three classical beams carrying a concentrated mass. Low and Dubey [12] presented shape functions for calculating the frequencies. Low [13] compared different models for simply supported beam. Özkaya and Pakdemirli [14] obtained the frequencies for the clamped-clamped beam with mass and searched approximate solutions of free and forced non-linear vibrations using a perturbation method. They compared the results with the solutions of artificial neural network method. Turhan [15] considered the longitudinal and transverse vibrations of bars and beams with a mass and torsional vibration of shafts with a disk. The natural frequencies were obtained using Rayleigh method and were compared with the exact solutions.

In this study, an Euler-Bernoulli type beam carrying a mass on different locations is considered. Transverse vibrations of the beam is investigated. For support conditions, six different cases are discussed. These cases are simple-simple, simplesliding, clamped-simple, clamped-clamped, clamped-sliding, sliding-sliding supports. In the analysis, finite element method is used to calculate the first five natural frequencies. 
Cubic interpolation function is assumed for the vertical displacement of the beam. Also linear bending is assumed. Results are compared with exact, approximate closed-form and Rayleigh's method solutions. It is found that the accuracy of finite element results are very high and closer to the exact frequency values than closed-form and Rayleigh solutions.

\section{FINITE ELEMENT FORMULATION}

In this part, the kinetic and elastic potential energies of the beam in transverse vibration will be given. The equations for natural frequencies will be obtained by using finite element method. Some assumptions are made in deriving the equations and in search of the solutions. The beam is assumed to have only vertical displacement, no elongation of neutral axis or movement in longitudinal direction is allowed. Cubic interpolation function for vertical displacement is assumed. For the beam shown in Figure 1, the kinetic and elastic potential energies without a concentrated mass are

$$
\begin{aligned}
& \mathrm{T}=\frac{1}{2} \rho \mathrm{A} \int_{0}^{\mathrm{L}_{\mathrm{T}}} \dot{\mathrm{v}}^{2} \mathrm{dx} \\
& \mathrm{U}=\frac{1}{2} \mathrm{EI} \int_{0}^{\mathrm{L}_{\mathrm{T}}} \mathrm{v}^{\prime \prime 2} \mathrm{dx}
\end{aligned}
$$

where $\rho$ is density, $A$ is cross-sectional area, $L_{T}$ is total length, $E I$ is flexural rigidity. $x$ and $\mathrm{z}$ denote longitudinal and vertical directions respectively and $\mathrm{v}$ denotes the displacement in $z$ direction. ()$\left.^{\prime}\right)$ and ()$^{\prime}$ denote differentiations with respect to time $t$ and $\mathrm{x}$ respectively. Since the longitudinal velocity component is very small, it is neglected in the kinetic energy equation. $x_{m}$ is the location of the concentrated mass $M_{c}$.

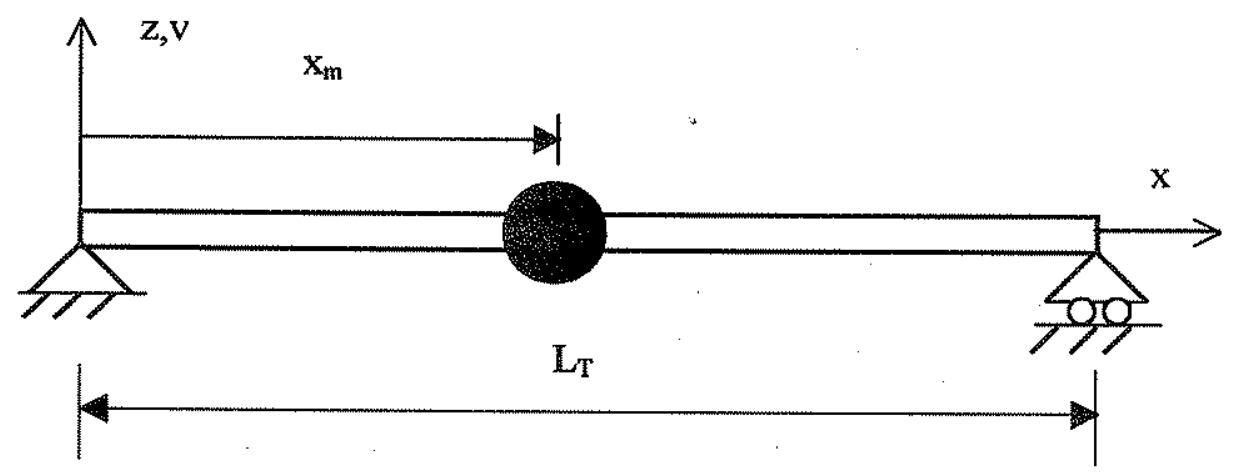

Figure 1. A beam with a concentrated mass on simple supports

For the finite element formulation, as a first step, one defines the degrees of freedom for a bending element in Figure $2 . v_{1}, v_{2}$ are the vertical displacements at the nodes 1 and 2 of the beam element respectively. $\theta_{1}$ and $\theta_{2}$ represent rotations of the nodes. $L$ is the length of the beam element. 


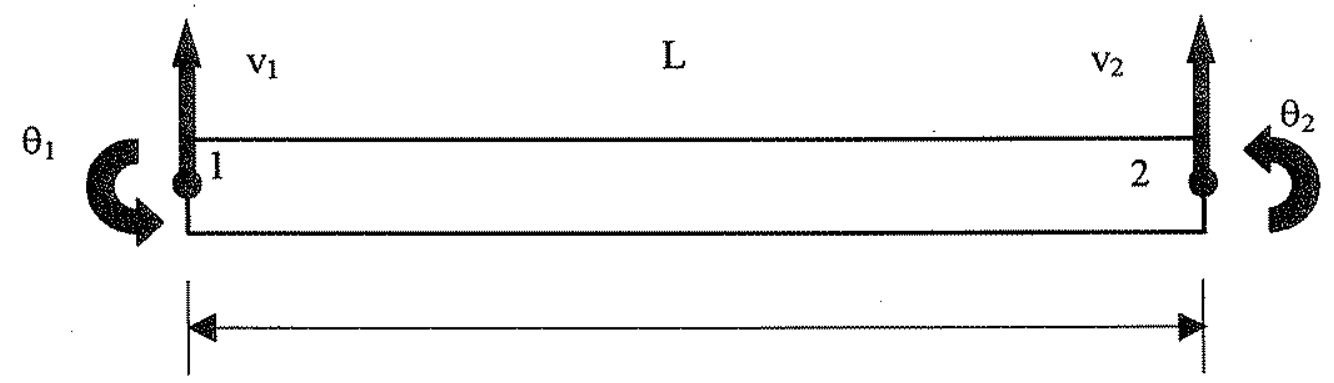

Figure 2. Beam bending element

Cubic interpolation function for the vertical displacement is

$v=\alpha_{1}+\alpha_{2} x+\alpha_{3} x^{2}+\alpha_{4} x^{3}$

Equation (3) can be written in matrix form as follows

$\{v\}=\left[\begin{array}{llll}1 & x & x^{2} & x^{3}\end{array}\left\{\begin{array}{l}\alpha_{1} \\ \alpha_{2} \\ \alpha_{3} \\ \alpha_{4}\end{array}\right\}\right.$

The nodal displacement vector for a bending element consists of vertical displacements and rotations at nodes 1 and 2

$\{v\}_{e}=\left\{\begin{array}{c}v_{1} \\ \theta_{1} \\ v_{2} \\ \theta_{2}\end{array}\right\}$

where rotation or slope of the beam is

$\theta_{\mathrm{r}}=\frac{\partial \mathrm{v}_{\mathrm{r}}}{\partial \mathrm{x}} \quad \mathrm{r}=1,2$

After applying finite element formulation, the kinetic and elastic potential energies for one element can be written as follows

$\left.\left.\mathrm{T}=\frac{1}{2}\{\dot{\mathrm{V}}\}_{\mathrm{e}}^{\mathrm{T}}[\mathrm{M}]\right\}_{\mathrm{v}}\right\}_{\mathrm{e}}$ 
$\mathrm{U}=\frac{1}{2}\{\mathrm{v}\}_{\mathrm{e}}^{\mathrm{T}}[\mathrm{K}]\{\mathrm{v}\}_{\mathrm{e}}$

where \{\}$^{\mathrm{T}}$ denotes transpose of the matrix and

$[K]_{e}=\frac{E I}{L^{3}}\left[\begin{array}{cccc}12 & 6 L & -12 & 6 L \\ 6 L & 4 L^{2} & -6 L & 2 L^{2} \\ -12 & -6 L & 12 & -6 L \\ 6 L & 2 L^{2} & -6 L & 4 L^{2}\end{array}\right]$

is the element stiffness matrix between nodes 1 and 2, and

$[M]_{\mathrm{e}}=\frac{\mathrm{mL}}{420}\left[\begin{array}{cccc}156 & 22 \mathrm{~L} & 54 & -13 \mathrm{~L} \\ 22 \mathrm{~L} & 4 \mathrm{~L}^{2} & 13 \mathrm{~L} & -3 \mathrm{~L}^{2} \\ 54 & 13 \mathrm{~L} & 156 & -22 \mathrm{~L} \\ -13 \mathrm{~L} & -3 \mathrm{~L}^{2} & -22 \mathrm{~L} & 4 \mathrm{~L}^{2}\end{array}\right]$

is the element inertia matrix where $m$ is mass per element length.

If the total length of the beam is considered, the element inertia and stiffness matrices must be combined and only one inertia and one stiffness matrix must be obtained. For the concentrated mass, a matrix with only one element is written for the location and this matrix is combined with system inertia matrix. The equation of motion can be obtained for free vibrations by applying Lagrange equation

$[\mathrm{M}]\{\ddot{v}\}+[\mathrm{K}]\{\mathrm{v}\}=\{0\}$

where $[M]$ and $[K]$ are the system inertia and stiffness matrices respectively, $\{v\}$ is system displacement vector. Assume a solution in the form of

$\{v\}=\{V\} e^{j \omega_{n} t}$

where $\mathrm{j}$ and $\omega_{\mathrm{n}}$ denote $\sqrt{-1}$ and natural frequencies and $\{\mathrm{V}\}$ is displacement amplitude vector. Substituting equation (12) into equation (11), one writes

$\left[[\mathrm{K}]-\omega_{\mathrm{n}}^{2}[\mathrm{M}]\right]\{\mathrm{V}\}=\{0\}$

For non-trivial solution, the determinant of coefficient matrix must be zero. This gives

$\left|[\mathrm{K}]-\omega_{\mathrm{n}}^{2}[\mathrm{M}]\right|=0$ 
Equation (14) is an eigenvalue problem and is to be solved for different end conditions and mass locations in the next section. The boundary conditions used in finite element analysis are as follows

Case 1. Simple-Simple Supports

$\mathrm{v}_{\mathrm{i}}=0, \mathrm{v}_{\mathrm{f}}=0$

Case 2. Simple-Sliding Supports

$\mathrm{v}_{\mathrm{i}}=0, \theta_{\mathrm{f}}=0$

Case 3. Clamped-Simple Supports

$\mathrm{v}_{\mathrm{i}}=0, \theta_{\mathrm{i}}=0, \mathrm{v}_{\mathrm{f}}=0$

Case 4. Clamped-Clamped Supports

$v_{i}=0, \theta_{i}=0, v_{f}=0, \theta_{f}=0$

Case 5. Clamped-Sliding Supports

$v_{i}=0, \theta_{i}=0, \theta_{\mathrm{f}}=0$

Case 6. Sliding-Sliding Supports

$\theta_{\mathrm{i}}=0, \theta_{\mathrm{f}}=0$

where $i$ and $f$ denote initial and final nodes of the beam.

\section{NUMERICAL SOLUTIONS}

Numerical values for the natural frequencies for the first five modes will be given in this section. Solutions of the eigenvalue problem (equation (14)) for different end conditions (equations (15-20)) and mass locations are presented in Tables 1-6. The dimensionless concentrated mass and its location can be written as follows

$\alpha=\frac{\mathrm{M}_{\mathrm{c}}}{\rho \mathrm{AL}_{\mathrm{T}}}$

$\eta=\frac{x_{m}}{L_{T}}$

In this study, the mass on the beam is assumed to have the same weight with the beam, namely $\alpha=1$. The analytical values (exact) were given by Özkaya et al. [10] and Özkaya and Pakdemirli [14]. The approximate closed form solutions were given by Low [13]. Rayleigh's quotient solutions were given by Turhan [15]. 40 elements are used in the finite element analysis. As can be seen from the tables, the finite element solutions are very accurate. If the number of elements are increased then the analysis will give better results. In ref. $[11,12,13]$ the natural frequencies for simply supported beams were given but their accuracy are lower than the finite element analysis. Also, frequency values obtained by Rayleigh's method in ref. [15] have less accuracy. 

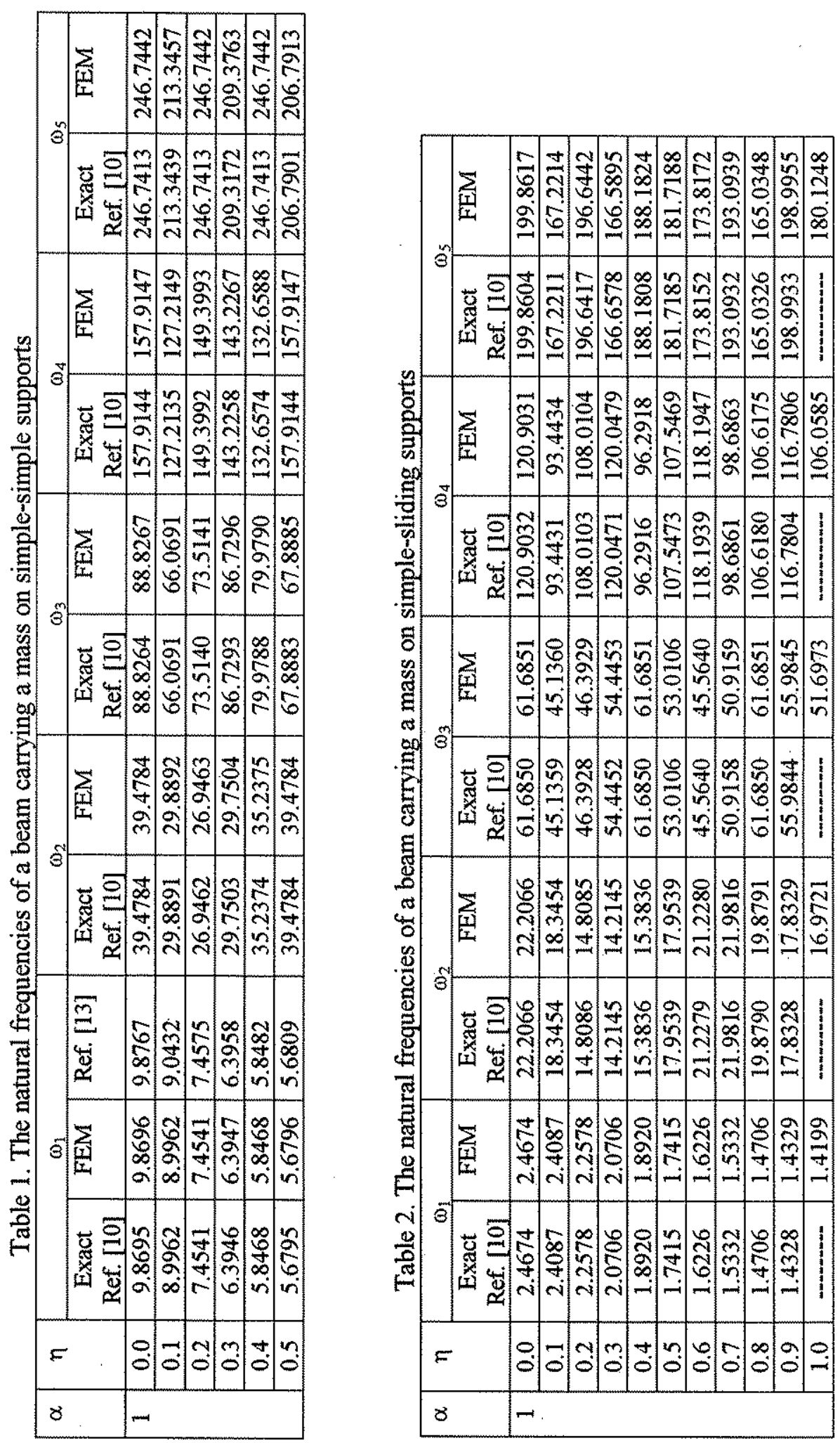

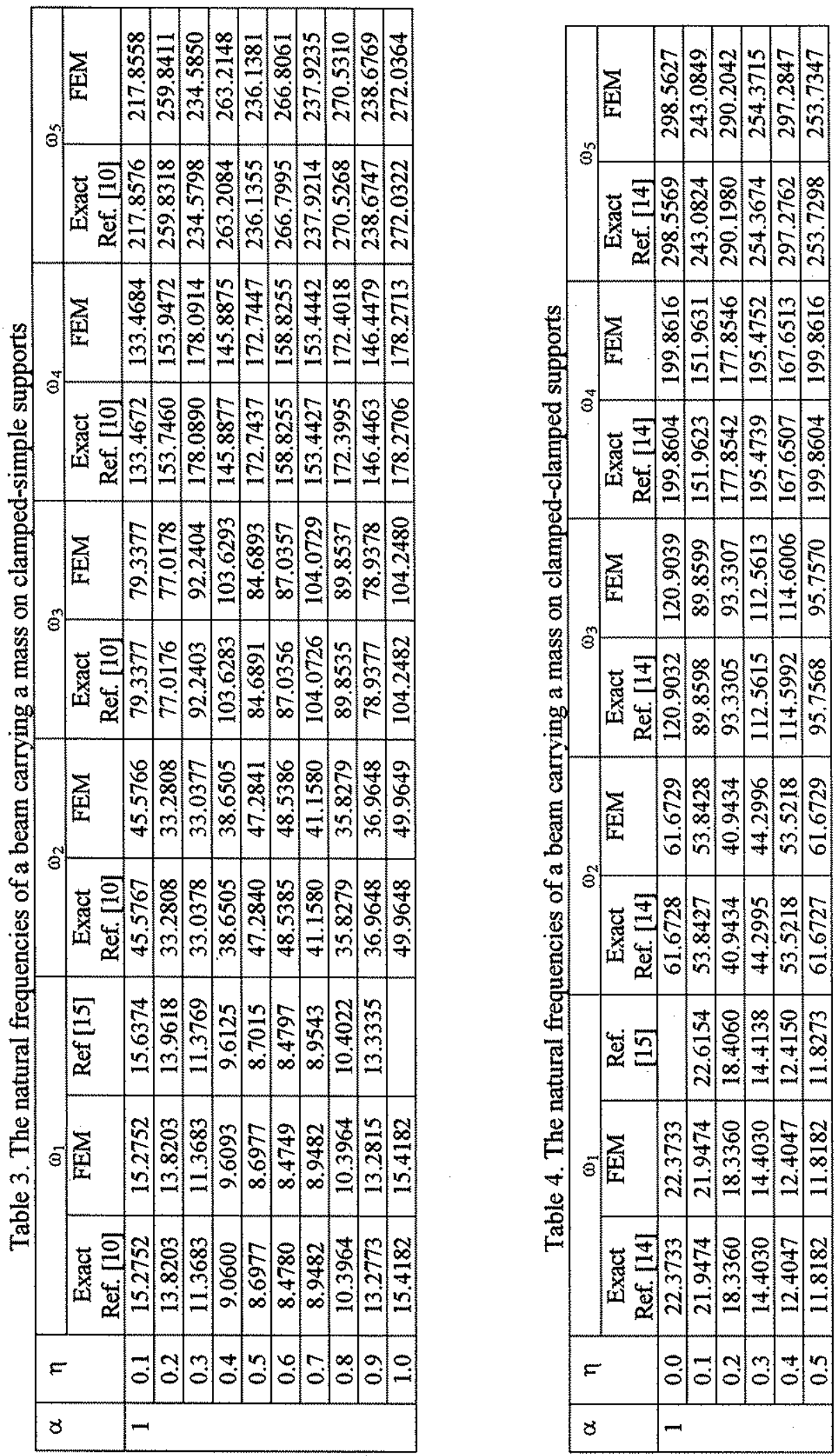

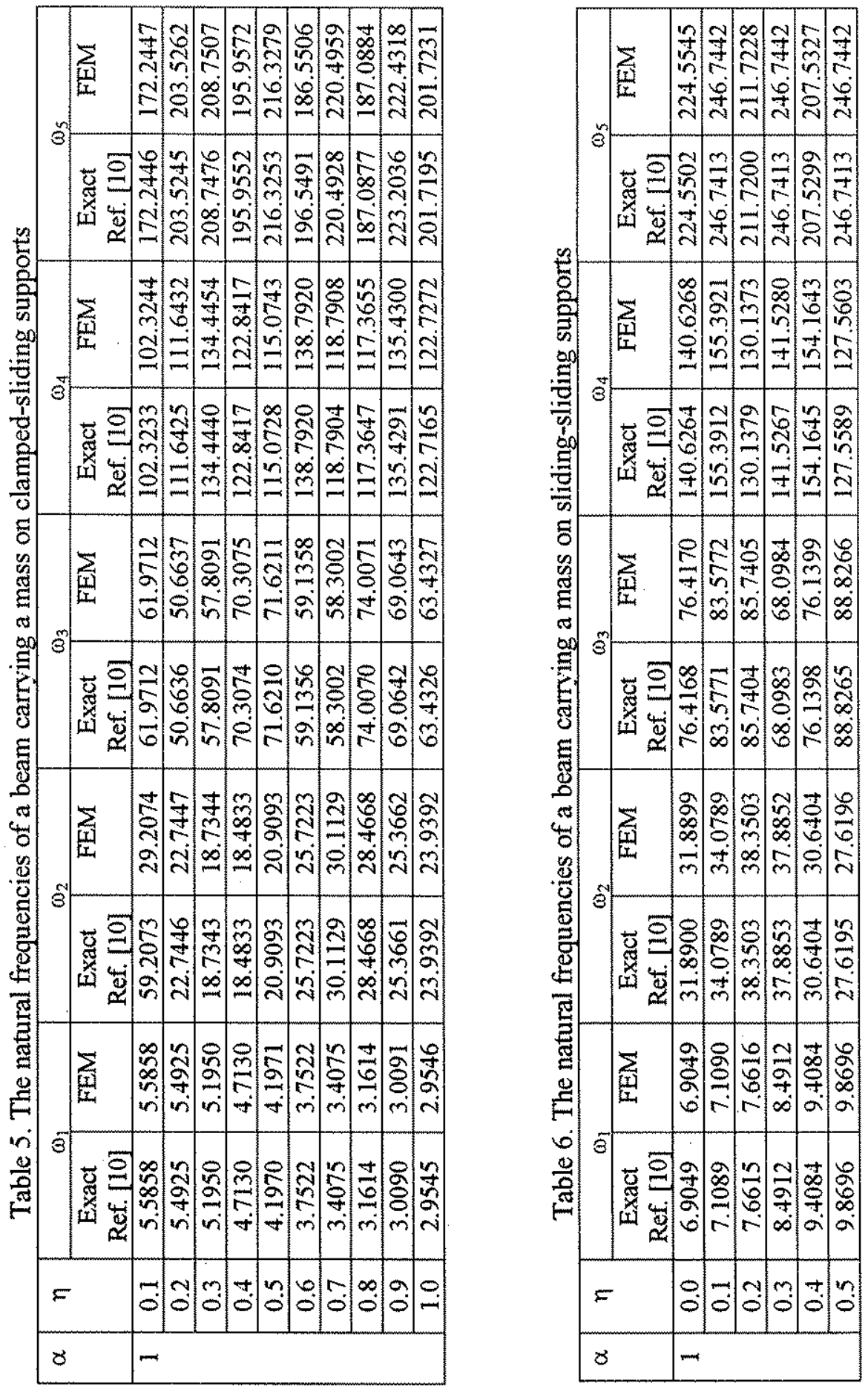


\section{CONCLUDING REMARKS}

The transverse vibrations of an Euler-Bernoulli type beam carrying a concentrated mass is considered. Six different boundary conditions and eleven different mass locations are assumed for the calculation of natural frequencies. The finite element method is used in the analysis. Cubic interpolation function for the vertical displacement is taken. The approximate results are compared with exact and other approximate solutions. The finite element method results are very close to the exact frequency values. Also increasing the number of elements in the analysis increases the accuracy of the natural frequencies.

\section{REFERENCES}

1. L. S. Srinath and Y. C. Das, Vibrations of beams carrying mass, Transaction of the American Society of Mechanical Engineers, Journal of Applied Mechanics, Series $\mathbf{E}$ 784-785, 1967.

2. J. H. Lau, Fundamental frequency of a constrained beam, Journal of Sound and Vibration 78, 154-157, 1981.

3. P. A. A. Laura, C. Filipich and V. H. Cortinez, Vibrations of beams and plates carrying concentrated masses, Journal of Sound and Vibration 117, 459-465, 1987.

4. W. H. Liu and F. H. Yeh, Free vibration of a restrained-uniform beam with intermediate masses, Journal of Sound and Vibration 117, 555-570, 1987.

5. M. J. Maurizi and P. M. Belles, Natural frequencies of the beam-mass system: comparison of the two fundamental theories of beam vibrations, Journal of Sound and Vibration 150, 330-334, 1991.

6. G. B. Chai and K. H. Low, On the natural frequencies of beams carrying a concentrated mass, Journal of Sound and Vibration 160, 161-166, 1993.

7. K. H. Low, T. M. Lim and G. B. Chai, Experimental and analytical investigations of vibration frequencies for center-loaded beams, Computers and Structures 48, 1157 $1162,1993$.

8. G. B. Chai, K. H. Low and T. M. Lim, Tension effects on the natural frequencies of centre-loaded clamped beams, Journal of Sound and Vibration 181, 727-736, 1995.

9. K. H. Low, R. N. Dubey and G. B. Chai, Experimental investigation and shape functions for lateral vibration of axially constrained beams with a concentrated mass at the centre, Journal of Sound and Vibration 202, 446-451, 1997.

10. E. Özkaya, M. Pakdemirli and H. R. Öz, Non-linear vibrations of a beam-mass system under different boundary conditions, Journal of Sound and Vibration 199, 679-696, 1997.

11. K. H. Low, Closed-form formulas for fundamental vibration frequency of beams under off-centre load, Journal of Sound and Vibration 201, 528-533, 1997.

12. K. H. Low and R. N. Dubey, A note on the fundamental shape function and frequency of beams under off-center load, Journal of Sound and Vibration 202, 134-138, 1997.

13. K. H. Low, Comments on "Non-linear vibrations of a beam-mass system under different boundary conditions", Journal of Sound and Vibration 207, 284-286, 1997.

14. E. Özkaya and M. Pakdemirli, Non-linear vibrations of a beam-mass system with both ends clamped, Journal of Sound and Vibration 221, 491-503, 1999.

15. Ö. Turhan, E. Altınsoy and S. İnceoğlu, Üzerinde tekil kütle taşıyan kiriş, çubuk ve millerin temel frekanslan için Rayleigh yaklaşıklıkları ve egzakt çözümler, 9. Illusal Makina Teorisi Sempozyumu 206-220, 1999. 